\title{
Tolerância À Interferência de Plantas Competidoras e Habilidade de Supressão por Cultivares de SoJa - I. Resposta de Variáveis de CRescimento ${ }^{1}$
}

\author{
Tolerance to Interference of Competing Plants and Supression Ability By Soybean Genotypes - \\ I. Growth Variables Response
}

LAMEGO, F.P. ${ }^{2}$, FLECK, N.G. ${ }^{3}$, BIANCHI, M.A. ${ }^{4}$ e VIDAL, R.A. ${ }^{3}$

\begin{abstract}
RESUMO - Características morfofisiológicas diferenciais de plantas podem influenciar as relações de competição entre cultura e plantas daninhas. O objetivo do presente trabalho foi avaliar a influência das características de plantas de quatro cultivares de soja sob competição ou não com outros dois cultivares de soja, simulando espécies daninhas dicotiledôneas, durante a fase vegetativa de crescimento. Para isso, conduziram-se dois experimentos: um em vasos, visando fornecer subsídios quanto ao crescimento inicial das plantas de soja; e outro em campo, a fim de acompanhar características de crescimento das plantas. Em campo, foram comparados os seguintes fatores e tratamentos: três condições de competição (ausência de plantas concorrentes; presença de plantas dos cultivares de soja BRS 205 ou Cobb); e quatro cultivares reagentes de soja à competição (IAS 5, BR-16, CD 205 e Fepagro RS-10). Cultivares de soja apresentaram variações na velocidade de emergência e de crescimento inicial de plantas. A presença de plantas concorrentes, independentemente das características próprias, afetou a ramificação da soja. Os cultivares Fepagro RS-10 e BR-16 apresentaram rápido crescimento durante a fase inicial de desenvolvimento; CD 205, ao contrário, mostrou lento crescimento nesta fase. Cultivares de soja de ciclo precoce cobriram com mais rapidez o solo durante os primeiros 45 dias do que os tardios.
\end{abstract}

Palavras-chave: competição, cultivares de soja, hábito de crescimento, estatura de planta.

\begin{abstract}
Differential morphological plant characteristics may influence competition relations between crop and weeds. The aim of this study was to evaluate the influence of plants of four soybean cultivars and two other soybean cultivars, mimicking dicotyledonous weed species, on their relationships during the vegetative growth period. Thus, two experiments were carried out: one in pots, to provide data for initial soybean plant growth; and the other in the field, to monitor plant growth characteristics. The following factors and treatments were tested in the field: three competition conditions (absence of competing plants or presence of the soybean cultivars BRS 205 or Cobb), and four soybean cultivars reagent to competition (IAS 5, BR-16, CD 205, and Fepagro $R S-10)$. Soybean cultivars showed varied emergence speed and initial plant growth. The presence of the concurrent plants, regardless of their plant characteristics, affected soybean branching. Fepagro RS-1O and BR-16 cultivars had a fast growth during the initial development period; CD 205, on the contrary, showed slow growth during this phase. Early maturity soybean cultivars cover the soil more rapidly than late maturity cultivars, during the first 45 days of growth.
\end{abstract}

Key words: competition, soybean cultivars, growth behavior, plant height.

Recebido para publicação em 18.8.2004 e na forma revisada em 5.9.2005.

2 Eng -Agra , aluna do Programa de Pós-Graduação em Fitotecnia da Universidade Federal do Rio Grande do Sul - UFRGS, Caixa Postal 15100, 91501-970 Porto Alegre-RS, <abilamego@yahoo.com.br>. ${ }^{3}$ Eng.-Agr., Ph.D., Prof. da Faculdade de Agronomia da UFRGS. Bolsista do CNPq, ${ }^{4}$ Eng.-Agr., Mestre, aluno do Programa de Pós-Graduação em Fitotecnia da UFRGS. 


\section{INTRODUÇÃO}

A posição que uma espécie ocupa numa comunidade vegetal, incluindo a localização no espaço e no tempo, e a função que ela exerce na comunidade representam seu nicho ecológico. Quanto maior for a sobreposição de nichos (semelhança entre espécies), mais intensa será a competição por recursos do meio (Radosevich et al., 1997).

Na cultura da soja, a competição com plantas daninhas é responsável por perdas relevantes na produtividade de grãos. Assim, o estresse causado à cultura pode expressar-se em alterações morfofisiológicas nas plantas, com reflexos na produtividade de grãos. No entanto, por ser uma espécie que apresenta características de plasticidade, a soja mostra respostas adaptativas às condições de ambiente e de manejo em que cresce (Melges et al., 1989).

Características morfofisiológicas das plantas influenciam as relações de competição entre cultura e plantas daninhas. A estatura de planta e o ciclo de desenvolvimento, por exemplo, são características que têm sido associadas positivamente com habilidade competitiva em soja; cultivares com maior duração de ciclo e estatura mais elevada reduzem a produção e o tamanho das sementes de plantas daninhas, devido ao incremento na competitividade da cultura (Bennett \& Shaw, 2000).

Na competição por luz, a maior estatura de planta da cultura relaciona-se inversamente com o crescimento de plantas daninhas, em razão do sombreamento que ela impõe aos seus vizinhos (Kwon et al., 1991). Todavia, plantas daninhas que apresentam elevada estatura perante a soja são capazes de sombreála e causar redução na produtividade da cultura. Por exemplo, a espécie daninha Cassia obtusifolia (fedegoso) superou a soja em estatura aos 70 dias após a emergência (DAE), sombreando a cultura durante o periodo reprodutivo, reduzindo assim a produtividade de grãos (Sims \& Oliver, 1990).

A presença de plantas daninhas nas lavouras pode alterar, além da quantidade, a qualidade da luz incidente no ambiente, afetando, desse modo, o desenvolvimento das plantas cultivadas (Ballaré \& Casal, 2000). A variação na qualidade da luz é percebida por pigmentos (fitocromo, criptocromo e fitotropina) mesmo antes de ocorrer o sombreamento e objetiva ajustar o crescimento da planta em função da presença de vizinhos. A relação da radiação vermelho extremo/vermelho, percebida pelos pigmentos, tem papel importante na indução de muitas alterações morfológicas na arquitetura das plantas, como crescimento do caule, dominância apical e ramificação (Ballare \& Casal, 2000). O sombreamento das plantas, detectado pela elevada radiação vermelho extremo, faz com que elas aloquem maior disponibilidade de recursos para investimento no crescimento da parte aérea, afetando o desenvolvimento do seu sistema radical e, nesse sentido, podendo comprometer a disputa por recursos do solo (Rajcan \& Swanton, 2001).

Caracteristicas iniciais vantajosas que favoreçam o crescimento são determinantes, porque é no período vegetativo que, em geral, se estabelecem as relações definitivas da competição entre plantas daninhas e cultivadas. Nessa fase, o cultivar com habilidade competitiva superior poderá manifestar seu potencial de supressão sobre plantas concorrentes. Dessa forma, este trabalho teve por objetivo avaliar a influência de características dissimilares em plantas de cultivares de soja, em resposta ao estresse competitivo imposto por genótipos de soja simuladores de plantas daninhas dicotiledôneas, na modificação de variáveis de crescimento da cultura.

\section{MATERIAL E MÉTODOS}

Foram realizados dois experimentos envolvendo habilidade competitiva entre cultivares de soja: um conduzido em telado e outro em campo. O trabalho em telado foi conduzido nos meses de outubro e novembro de 2002, na Faculdade de Agronomia da UFRGS, em Porto Alegre-RS. O experimento foi instalado em vasos com volume de $4 \mathrm{~L}$ e diâmetro de $0,18 \mathrm{~m}$, utilizando-se solo como substrato. Os cultivares de soja utilizados foram: IAS 5, BR-16, CD 205, Fepagro RS-10, BRS 205 e Cobb, os quais constituíram os tratamentos. O delineamento experimental foi o completamente casualizado, com cinco repetições. Foram colocadas oito sementes de cada cultivar de soja por vaso 
e, dez dias após a semeadura (DAS), realizou-se desbaste do excesso das plantas, mantendo-se quatro plantas por vaso.

Avaliou-se a velocidade de emergência dos cultivares através da contagem diária das plântulas emergidas até o décimo DAS. Para o cálculo do índice de velocidade de emergência (IVE) foi utilizada equação referida por Popinigis (1977), em que IVE $=\mathrm{N}_{1} / \mathrm{D}_{1}+\mathrm{N}_{2} / \mathrm{D}_{2}$ $+\ldots \mathrm{N}_{\mathrm{n}} / \mathrm{D}_{\mathrm{n}}$, sendo $\mathrm{N}_{1}=$ número de plântulas emergidas no primeiro dia; $\mathrm{N}_{\mathrm{n}}=$ número acumulado de plântulas emergidas no dia $\mathrm{n} ; \mathrm{D}_{1}=$ primeiro dia de contagem; e $\mathrm{D}_{\mathrm{n}}=$ número final de dias contados. Aos 28 DAS foram realizadas as seguintes determinações: estatura de planta, área foliar e massa seca das partes aérea e radical.

O experimento em campo foi conduzido no ano agrícola 2002/03, na Estação Experimental Agronômica da UFRGS (EEA), em Eldorado do Sul - RS. O solo da área experimental é classificado como Latossolo Vermelho Distrófico típico, pertencendo à unidade de mapeamento São Jerônimo (Embrapa, 1999).

O delineamento experimental usado foi blocos casualizados, com quatro repetições, com parcelas subdivididas, em que diferentes condições de competição foram dispostas nas parcelas principais, e os cultivares reagentes de soja, nas subparcelas. Os fatores e tratamentos comparados foram: três condições de competição [ausência de plantas concorrentes e presença do cultivar de soja competidor BRS 205 (ciclo semiprecoce e baixa estatura) ou Cobb (tardio e alto)]; e quatro cultivares reagentes de soja [IAS 5 (precoce e baixa), BR-16 (semiprecoce e alta), CD 205 (tardia e média) e RS-10 (tardia e alta)]. Cada unidade experimental mediu $16 \mathrm{~m}^{2}$ (4 x $\left.4 \mathrm{~m}\right)$, constando de dez fileiras de soja espaçadas de $0,4 \mathrm{~m}$, sendo a área útil de $3,84 \mathrm{~m}^{2}(1,6 \times 2,4 \mathrm{~m})$.

O experimento foi conduzido em sistema de semeadura direta, em área onde houve cultivo anterior da associação de aveia-preta (Avena strigosa) e ervilhaca (Vicia sativa). O manejo das espécies de cobertura e da vegetação espontânea foi feito através de duas aplicações do herbicida glyphosate (nas doses de $1.080 \mathrm{~g}$ e $900 \mathrm{~g}$ de equivalente ácido por hectare, respectivamente). A adubação do solo foi efetuada 13 dias antes da semeadura, por ocasião da rolagem mecânica da cobertura vegetal, realizada entre as duas dessecações. Realizou-se aplicação do adubo a lanço, em superfície, distribuindo-se $300 \mathrm{~kg} \mathrm{ha}^{-1} \mathrm{da}$ fórmula 5-30-15, o que correspondeu à adição de 15,90 e $45 \mathrm{~kg} \mathrm{ha}^{-1}$ de $\mathrm{N}, \mathrm{P}_{2} \mathrm{O}_{5}$ e $\mathrm{K}_{2} \mathrm{O}$, respectivamente.

A semeadura da soja foi realizada no dia 6 de novembro de 2002, sendo ajustada de acordo com o poder germinativo dos cultivares, objetivando-se alcançar densidade de 40 plantas $\mathrm{m}^{-2}$. Os cultivares concorrentes (BRS 205 e Cobb) foram semeados no sentido transversal ao das linhas dos cultivares, também no espaçamento de $0,4 \mathrm{~m}$, de modo a se obter densidade de 20 plantas $\mathrm{m}^{-2}$. A emergência da soja foi acompanhada através de contagens das plantas aos 7 e 14 DAS, em área amostrada de $0,8 \mathrm{~m}^{2}$ por subparcela.

O controle de plantas daninhas na área do experimento foi feito em pós-emergência, através da aplicação dos herbicidas clethodim (240 $\mathrm{g} \mathrm{ha}^{-1}$ ) e bentazon (600 $\mathrm{g} \mathrm{ha}^{-1}$ ), visando eliminar espécies daninhas gramíneas e dicotiledôneas, respectivamente. Durante os meses de janeiro e fevereiro foram realizadas, quando necessárias, suplementações hídricas por meio de irrigações.

As variáveis avaliadas, tomadas nas subparcelas em que os cultivares reagentes e competidores cresciam exclusivos, foram: estatura de planta, massa seca dos ramos desprovidos de folhas, massa seca das folhas dos ramos, número e comprimento de ramos e cobertura foliar do solo. Para determinação da estatura de planta foram escolhidas, ao acaso, oito plantas na área útil de cada subparcela. A estatura da soja foi mensurada a cada duas semanas, medindo-se a distância desde a base da planta até o último nó desenvolvido no caule das plantas.

Para obtenção das massas secas de ramos e de folhas de ramos, aos 45 e $60 \mathrm{DAE}$, foram selecionadas três fileiras de soja, onde eram coletadas, ao acaso, três plantas de soja em cada fileira, fora da área destinada à produtividade. Em seguida, as plantas eram separadas em folhas dos ramos e ramos sem folhas, que foram secos em estufa a $60{ }^{\circ} \mathrm{C}$, até se obter peso constante de suas massas. Todos os ramos presentes nas plantas foram contados 
e medidos, estabelecendo-se o número e o comprimento médio dos ramos por planta $(\mathrm{cm})$.

A cobertura foliar do solo pelos cultivares reagentes e competidores foi avaliada aos 30 , 45 e 60 DAE, de modo visual, fotográfico e misto. A avaliação visual foi feita utilizandose escala percentual, em que a nota zero correspondeu à ausência de cobertura do solo pelo dossel das plantas e a nota 100 significou cobertura completa, sendo realizada por dois avaliadores. Para avaliação fotográfica foi fotografada uma área de $0,4 \mathrm{~m}^{2}$ em cada unidade experimental. Com auxílio do programa computacional Adobe PhotoDeluxe 2.0, as fotos foram digitalizadas e, posteriormente, estimou-se a participação da área ocupada pelo dossel do cultivar em relação à área total amostrada, com auxílio do programa Sigma Scan. Na avaliação da cobertura pelo método misto foram atribuídas notas visuais às fotos obtidas com o método fotográfico. Nesse processo, utilizou-se novamente a mesma escala percentual indicada acima.

Os dados de estatura de planta, determinada periodicamente, foram ajustados ao modelo logístico, com auxílio do programa computacional Sigma Plot versão 5.0: $Y=$ $a /\left[1+(X / X o)^{b}\right]$, em que: $Y=$ estatura de planta $(\mathrm{cm}) ; a=$ máximo $Y ; b=$ assíntota do modelo; $X$ = épocas de avaliação (dias após a emergência); e $X_{0}=$ metade do período global de mensuração da estatura de planta. Os valores de estatura ajustados pelo modelo logístico foram expressos em função de DAE e, também, de graus-dia: $\left.\left.G D=\Sigma\left(\left(t_{\max }-t_{\min }\right) / 2\right)\right)-t_{b}\right)$, em que: $\mathrm{GD}=$ soma de graus-dia $\left({ }^{\circ} \mathrm{C}\right) ; \mathrm{t}_{\max }=$ temperatura máxima do ar na EEA/UFRGS, diária; $\mathrm{t}_{\min }=$ temperatura minima do ar na EEA/ UFRGS, diária; e $t_{b}=$ temperatura-base de crescimento da soja $\left(10^{\circ} \mathrm{C}\right)$, conforme referido por Silva (1984).

As variáveis avaliadas quando as plantas de ambos os grupos de cultivares, reagentes e competidores, encontravam-se no estádio $\mathrm{R}_{8}$, tanto crescendo em associação quanto isolados, foram a estatura de planta e o número e comprimento de ramos. Para sua obtenção foram coletadas cinco plantas, seqüencialmente, fora da área destinada à produtividade, sendo medidas as respectivas áreas abrangidas pelas amostras. Nas determinações dessas variáveis foram adotados os mesmos procedimentos já descritos. Tanto o número quanto o comprimento dos ramos foram expressos com base na área ocupada pelas plantas amostradas nas subparcelas.

Os dados referentes aos experimentos em telado e em campo, quando cultivares reagentes e simuladores cresciam isoladamente, foram submetidos à análise de variância, através do teste $\mathrm{F}$, adotando-se o nível de 5\% de probabilidade. Em telado, as médias dos tratamentos foram comparadas aplicando-se o teste de Duncan, também a 5\% de probabilidade. Em campo, constatando-se significância, os tratamentos foram agrupados e comparados por meio de contrastes ortogonais (Tabela 1), também a 5\% de probabilidade. Para as variáveis derivadas da combinação dos fatores condições de competição e cultivares reagentes, os dados foram submetidos à análise de variância, através do teste $\mathrm{F}$, adotando-se como limites de aceitação o nível de 5\% de probabilidade para significância de efeitos individuais de fatores e o de $10 \%$ para os casos de interação (Riboldi, 1993). As médias dos tratamentos foram comparadas aplicando-se o teste de Duncan, adotando-se o nivel de 5\% de probabilidade. A análise estatística foi feita com o auxílio do programa computacional SAS (SAS, 1989).

\section{RESULTADOS E DISCUSSÃO}

\section{Experimento em telado}

Houve variação na velocidade de emergência entre os cultivares de soja avaliados em telado (Tabela 2). Os cultivares de ciclo mais tardio (CD 205, Fepagro RS-10 e Cobb) apresentaram mais rápida emergência do que os precoces BRS 205 e BR-16; já o IAS 5 ficou em posição intermediária. Vale enfatizar que plantas portadoras de elevada velocidade de emergência e de rápido crescimento inicial utilizam prioritariamente os recursos do meio e, assim, geralmente, tornam-se mais competitivas (Firbank \& Watkinson, 1985).

A velocidade de emergência das sementes associa-se à sua qualidade fisiológica e genética e, também, aos fatores do ambiente (Bewley, 1997). No presente trabalho, as sementes dos cultivares de soja avaliados no experimento em telado foram submetidas, 
Tabela 1 - Coeficientes para os contrastes ortogonais testados em estudo de competição entre cultivares de soja reagentes e simuladores de plantas daninhas. EEA/UFRGS, Eldorado do Sul-RS, 2002/03

\begin{tabular}{|c|c|c|c|c|c|}
\hline \multirow{2}{*}{ Tratamento } & \multicolumn{5}{|c|}{ Contraste } \\
\hline & 1 & 2 & 3 & 4 & 5 \\
\hline \multicolumn{6}{|l|}{ Cultivares reagentes: } \\
\hline 1. IAS 5 , ciclo precoce, baixa estatura & + & + & + & & \\
\hline 2. BR-16, ciclo semiprecoce, alta estatura & + & + & - & & \\
\hline 3. CD 205, ciclo tardio, média estatura & + & - & & + & \\
\hline 4. Fepagro RS-10, ciclo tardio, alta estatura & + & - & & - & \\
\hline \multicolumn{6}{|l|}{ Cultivares competidores: } \\
\hline 5. BRS 205, ciclo semiprecoce, baixa estatura & - & & & & + \\
\hline 6. Cobb, ciclo tardio, alta estatura & - & & & & - \\
\hline
\end{tabular}

Tabela 2 - Valores médios para índice de velocidade de emergência e massa seca das partes aérea e radical, estatura de planta, área foliar e relação massa radical/massa aérea de cultivares de soja avaliados 28 dias após a semeadura. UFRGS, Porto Alegre-RS, 2002

\begin{tabular}{|l|c|c|c|c|c|c|}
\hline $\begin{array}{c}\text { Cultivar de soja } \\
\text { avaliado }\end{array}$ & IVE $^{1 /}$ & $\begin{array}{c}\text { Estatura de } \\
\text { planta }(\mathrm{cm})\end{array}$ & $\begin{array}{c}\text { Área foliar } \\
\left(\mathrm{cm}^{2} \text { por planta }\right)\end{array}$ & $\begin{array}{c}\text { Massa aérea } \\
\text { (g por planta) }\end{array}$ & $\begin{array}{c}\text { Massa radical } \\
\text { (g por planta) }\end{array}$ & $\begin{array}{c}\text { Massa radical/ } \\
\text { massa aérea }\end{array}$ \\
\hline IAS 5 & $7,23 \mathrm{ab}^{2 /}$ & $10,6 \mathrm{c}$ & $82,2 \mathrm{a}$ & $0,55 \mathrm{~b}$ & $0,35 \mathrm{bc}$ & $0,64 \mathrm{~cd}$ \\
\hline BR-16 & $4,92 \mathrm{c}$ & $13,0 \mathrm{a}$ & $83,7 \mathrm{a}$ & $0,55 \mathrm{~b}$ & $0,37 \mathrm{~b}$ & $0,67 \mathrm{bcd}$ \\
\hline CD 205 & $7,78 \mathrm{a}$ & $11,3 \mathrm{bc}$ & $58,8 \mathrm{~b}$ & $0,39 \mathrm{c}$ & $0,30 \mathrm{c}$ & $0,77 \mathrm{a}$ \\
\hline Fepagro RS-10 & $7,85 \mathrm{a}$ & $13,4 \mathrm{a}$ & $87,9 \mathrm{a}$ & $0,66 \mathrm{a}$ & $0,41 \mathrm{ab}$ & $0,62 \mathrm{~d}$ \\
\hline BRS 205 & $6,43 \mathrm{~b}$ & $12,0 \mathrm{~b}$ & $82,8 \mathrm{a}$ & $0,61 \mathrm{ab}$ & $0,44 \mathrm{a}$ & $0,73 \mathrm{ab}$ \\
\hline Cobb & $7,71 \mathrm{a}$ & $11,0 \mathrm{c}$ & $77,1 \mathrm{a}$ & $0,53 \mathrm{~b}$ & $0,38 \mathrm{~b}$ & $0,71 \mathrm{abc}$ \\
\hline Médias & 6,98 & 11,9 & 78,8 & 0,55 & 0,38 & 0,69 \\
\hline CV $(\%)$ & 13,17 & 5,12 & 9,89 & 11,38 & 11,54 & 7,42 \\
\hline
\end{tabular}

1/ Índice de velocidade de emergência.

2/ Médias seguidas de mesma letra, nas colunas, não diferem entre si pelo teste de Duncan a $5 \%$ de probabilidade.

inicialmente, ao teste de vigor de envelhecimento acelerado, bem como ao teste de germinação (dados não mostrados). Embora não tenham sido constatadas diferenças entre os cultivares em ambos os testes, não se pode desconsiderar a influência que o ambiente exerce sobre a formação e maturação das sementes, com conseqüente efeito sobre sua qualidade. Assim, as diferenças observadas para o indice de velocidade de emergência podem ser atribuídas, em especial, a fatores genéticos dos cultivares, sem desconsiderar, contudo, a interferência exercida por fatores ambientais.

Aos 28 DAS, Fepagro RS-10 e BR-16 foram os cultivares que apresentaram maiores estaturas de planta, enquanto IAS 5 e Cobb foram os mais baixos (Tabela 2). Em relação à área foliar, os cultivares mostraram equivalência, exceto $C D$ 205, que ficou em posição inferior à dos demais. O cultivar de soja Cobb possui estatura elevada (Figura 2), porém a baixa estatura que mostrou aos 28 DAS demonstra um lento crescimento inicial para a variável em questão, o que o torna potencialmente vulnerável aos efeitos de competição por luz nessa fase. Paralelamente à estatura de planta, o acúmulo de área foliar também apresenta influência relevante sobre a capacidade das plantas em sombrear seus vizinhos (Fischer \& Miles, 1973).

Os cultivares RS-10 e BRS 205 acumularam as maiores quantidades de massa aérea e massa radical, respectivamente, enquanto 
CD 205 mostrou as menores (Tabela 2). Por outro lado, os cultivares CD 205 e BRS 205 apresentaram maiores relações massa radical/massa aérea do que RS-10 e IAS 5, enquanto Cobb e BR-16 situaram-se em posição intermediária à daqueles.

Dentre os três cultivares que se destacaram, inicialmente, pelo elevado IVE, apenas RS-10 manteve posição de vantagem posteriormente, sobressaindo, também, quanto às demais variáveis avaliadas (desconsiderandose a relação massa radical/massa aérea). O comportamento apresentado por RS-10 mostra que ele possui elevada habilidade em competir precocemente com as plantas concorrentes, ao apresentar rápido crescimento, investindo na produção de massa na parte aérea das plantas, através de área foliar e estatura elevadas. O cultivar CD 205, que também alcançou elevado IVE, apresentou, no geral, padrão de lento crescimento no período avaliado. O comportamento deste cultivar, ao contrário de RS-10, pode comprometer sua habilidade competitiva pelo recurso luz na fase inicial do ciclo.

O estabelecimento precoce de cultivares de soja através de elevada velocidade de emergência e rápido crescimento inicial, investindo em estatura, área foliar e massa, é garantia de habilidade competitiva superior à de plantas daninhas em estádios iniciais de desenvolvimento da cultura (Bennett \& Shaw, 2000; Horak \& Loughin, 2000). Nesse sentido, características que podem conferir à soja maior precocidade competitiva com plantas daninhas, particularmente em relação ao recurso luz, geralmente estiveram associadas ao cultivar RS-10.

\section{Experimento em campo}

Não foram constatadas diferenças significativas entre as populações de plantas dos cultivares reagentes e entre aquelas dos simuladores nas avaliações realizadas aos 7 e 14 DAS. Contudo, o percentual de plantas dos cultivares reagentes emergidos aos 7 DAS, comparativamente à população encontrada aos 14 DAS, indica que RS-10 apresentou maior $(23,6 \%)$ velocidade inicial de emergência do que BR-16 (9,7\%). Esses resultados corroboram, parcialmente, aqueles encontrados no experi- mento em telado, em que BR-16 apresentou baixo IVE.

Para a variável cobertura do solo, independentemente do método de avaliação utilizado para a estimar, até os $45 \mathrm{DAE}$ os cultivares reagentes de ciclo precoce superaram os de ciclo tardio (Figura 1). Já aos 60 DAE os resultados se inverteram. Cultivar de soja que cubra precocemente as entrelinhas, com rápido fechamento do dossel, pode suprimir o crescimento de plantas daninhas (Wax \& Pendleton, 1968). Do mesmo modo, Balbinot Jr. et al. (2003) constataram que a cobertura precoce do solo por cultivares de arroz relacionou-se com maior habilidade competitiva.

Os dados referentes à evolução da estatura de planta dos cultivares testados ajustaramse satisfatoriamente ao modelo logístico (Figura 2). O cultivar CD 205, embora possa ser classificado como de média estatura (Reunião..., 2003), em torno de 60 DAE passou a superar os demais nesta característica, atingindo a maior estatura de planta. Observase que, até aproximadamente $45 \mathrm{DAE}$, os precoces IAS 5 e BRS 205 apresentaram certa vantagem em estatura sobre os tardios CD 205 e Cobb; a partir de então passaram a ser superados pelos dois últimos. Por sua vez, BR-16 suplantou CD 205 e Cobb até cerca de $60 \mathrm{DAE}$, quando então passou a ser superado em estatura pelos dois tardios.

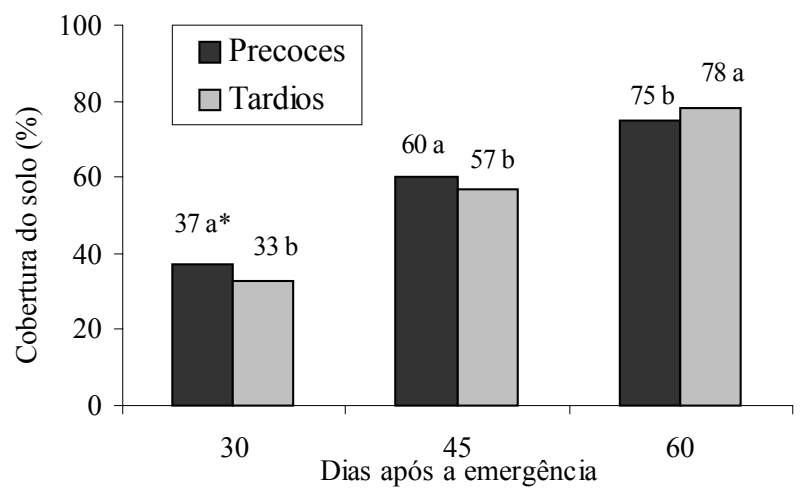

Figura 1 - Cobertura do solo formada pelo dossel de cultivares de soja de ciclos precoce (IAS 5 e BR-16) ou tardio (CD 205 e Fepagro RS-10), médias de três métodos de avaliação, EEA/UFRGS, Eldorado do Sul-RS, 2002/03 (*Médias seguidas de mesma letra não diferem pelo teste de Duncan a $5 \%$ de probabilidade. Coeficientes de variação de 2,8, 2,1 e $1,0 \%$, respectivamente). 


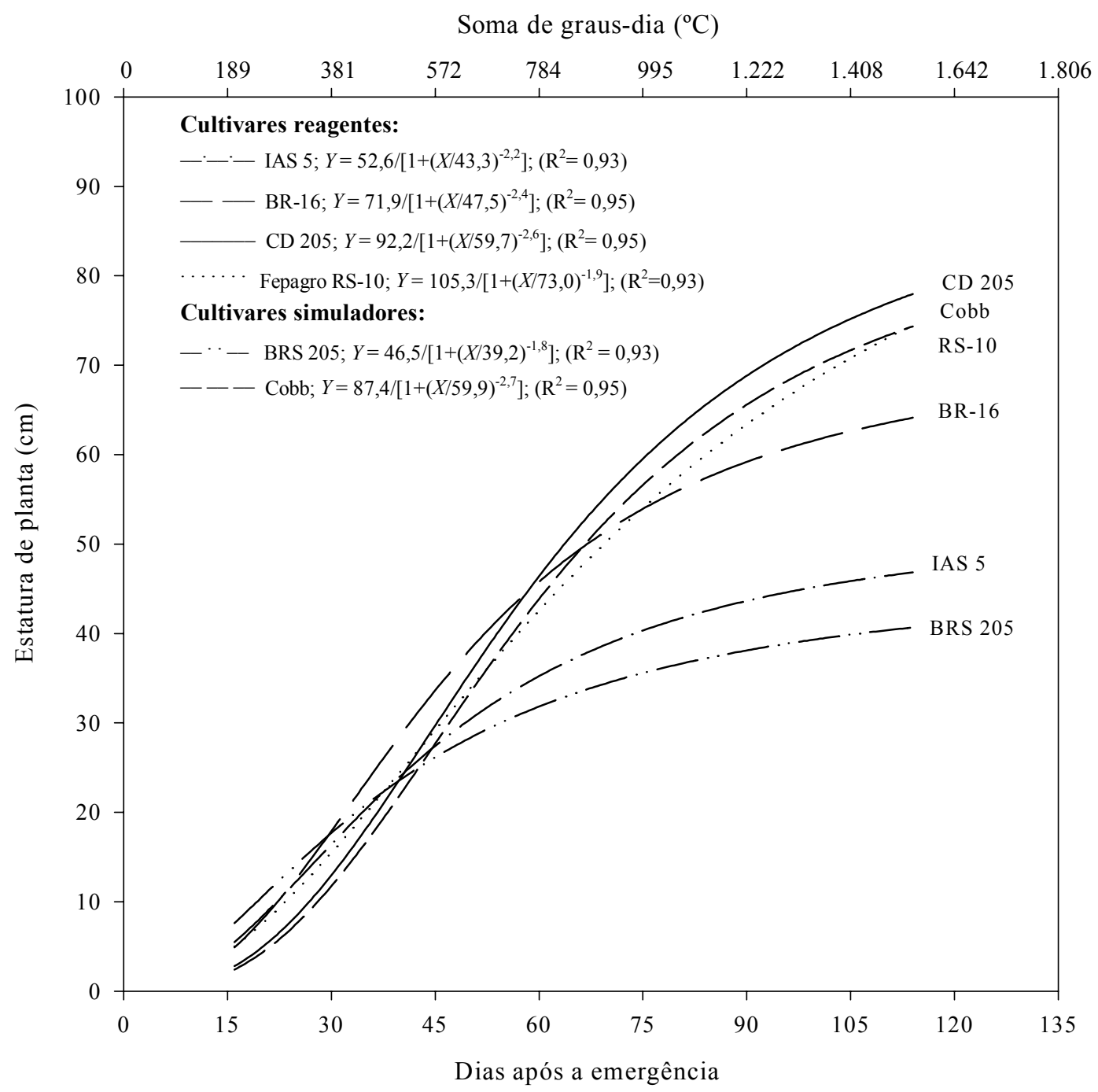

Figura 2 - Evolução da estatura de planta de cultivares de soja reagentes e simuladores de plantas daninhas quando em monocultivo. EEA/UFRGS, Eldorado do Sul-RS, 2002/03.

Em relação à estatura dos cultivares simuladores de plantas concorrentes, BRS 205 demonstrou baixo potencial de competição por luz, visto que apresentou a menor estatura entre todos os genótipos avaliados (Figura 2). No entanto, em telado, ele mostrou acúmulo relativamente elevado de massa radicular em estádios iniciais, o que pode lhe conferir vantagem na captação de recursos do solo. Quanto ao Cobb, este atingiu elevada estatura final de planta, mas, ao menos durante os primeiros 45 dias de ciclo, seu lento crescimento foi-lhe desvantajoso para uma eficiente concorrência por luz no período.
Na pré-colheita (estádio fenológico $\mathrm{R}_{8}$ ), não houve interação para os fatores condições de competição x cultivares reagentes para estatura, sendo significativas apenas as diferenças entre cultivares (dados não mostrados). No que se refere aos dados observados para estatura de planta ao longo do ciclo de desenvolvimento dos cultivares, os tardios CD 205 e RS-10 não diferiram entre si, atingindo as maiores estaturas, consideradas as médias das três condições de competição. Por sua vez, IAS 5 desenvolveu a menor estatura e BR-16 foi intermediário aos demais (dados não mostrados).

Planta Daninha, Viçosa-MG, v. 23, n. 3, p. 405-414, 2005 
Resultados de contrastes ortogonais efetuados para características morfofisiológicas dos cultivares são encontrados na Tabela 3 . As massas secas de ramos e de folhas de ramos dos cultivares simuladores superaram amplamente as dos reagentes aos $45 \mathrm{DAE}$, fato que seria previsivel, considerando-se as diferenças nas populações de plantas dos dois grupos de cultivares. Entre os cultivares reagentes, aos 45 DAE, o grupo dos precoces (IAS 5 e BR-16) superou o dos tardios (CD 205 e RS-10) para as variáveis massas secas de ramos $(+29 \%)$ e de folhas de ramos (+25\%). No entanto, aos $60 \mathrm{DAE}$, os precoces superaram os tardios apenas quanto à massa seca de folhas dos ramos $(+21 \%)$. O maior acúmulo de massa de ramos e de folhas de ramos pelos cultivares precoces deve-se ao fato de que, em geral, eles apresentam crescimento inicial mais acelerado, em razão do menor ciclo de desenvolvimento. Embora, aos $60 \mathrm{DAE}$, tardios e precoces tenham apresentado acúmulo de massa de ramos equivalente, estes últimos ainda foram superiores em massa de folhas de ramos, o que pode se constituir em vantagem no sombreamento de plantas concorrentes.

Ocorreram diferenças entre cultivares reagentes precoces e tardios em relação ao número de ramos por planta, em que o grupo dos precoces superou o dos tardios em ambas as avaliações efetuadas (Tabela 3). Houve diferenças entre os cultivares tardios para número de ramos por planta aos $45 \mathrm{DAE}$, com CD 205 superando RS-10, e, também, entre os simuladores, com BRS 205 superando Cobb essas diferenças não se mantiveram aos 60 DAE.

Em se tratando de cultivares reagentes, não houve interação para os fatores condições de competição e cultivares reagentes no que se refere às variáveis número e comprimento de ramos por área, avaliados na pré-colheita (estádio fenológico $\mathrm{R}_{8}$ ); contudo, foram significativas as diferenças entre condições de competição (Figura 3). Para ambas as variáveis, comparativamente à situação de ausência de competição, reduziram-se de modo equivalente os valores obtidos quando os cultivares reagentes estiveram associados aos simuladores BRS 205 ou Cobb.

Independentemente do simulador que esteve presente, os cultivares reagentes responderam ao estresse competitivo causado pela presença dos simuladores, reduzindo tanto o número quanto o comprimento de ramificações nas plantas. Embora os simuladores de plantas concorrentes (BRS 205 e Cobb) tenham apresentado características dissimilares, como em crescimento inicial, estatura de planta e ciclo, ambos induziram basicamente as mesmas respostas aos cultivares reagentes. É provável que os coeficientes de variação elevados (Figura 3), para as

Tabela 3 - Médias e significância estatística dos contrastes ortogonais testados para características de planta de cultivares de soja reagentes (IAS 5, BR-16, CD 205 e Fepagro RS-10) e simuladores de plantas daninhas (BRS 205 e Cobb), quando em monocultivo. EEA/UFRGS, Eldorado do Sul-RS, 2002/03

\begin{tabular}{|c|c|c|c|c|c|c|}
\hline \multirow{2}{*}{ Característica } & \multicolumn{6}{|c|}{ Contrastes ortogonais } \\
\hline & $(1 \mathrm{a} 4) \times(5+6)^{1 /}$ & $(1+2) \times(3+4)$ & $(1 \times 2)$ & $(3 \times 4)$ & $(5 \times 6)$ & CV $(\%)$ \\
\hline $\begin{array}{l}\text { Massa seca de ramos } \\
\text { (mg por planta) - } 45 \mathrm{DAE}^{2 /}\end{array}$ & $154 \times 454 *$ & $173 \times 134 *$ & $178 \times 168^{\text {ns }}$ & $157 \times 112^{\mathrm{ns}}$ & $527 \times 382^{\text {ns }}$ & 52,05 \\
\hline $\begin{array}{l}\text { Massa seca de ramos } \\
\text { (mg por planta) -60 DAE }\end{array}$ & $846 \times 1691^{\mathrm{ns}}$ & $751 \times 942^{\text {ns }}$ & $861 \times 642^{\text {ns }}$ & $1164 \times 719^{\text {ns }}$ & $2013 \times 1369^{\mathrm{ns}}$ & 56,49 \\
\hline $\begin{array}{l}\text { Massa seca de folhas de ramos } \\
\text { (mg por planta) - 45 DAE }\end{array}$ & $212 \times 710^{*}$ & $236 \times 188^{*}$ & $267 \times 206^{\text {ns }}$ & $206 \times 169 *$ & $849 \times 571^{\text {ns }}$ & 48,35 \\
\hline $\begin{array}{l}\text { Massa seca de folhas de ramos } \\
\text { (mg por planta)- } 60 \text { DAE }\end{array}$ & $756 \times 1550^{\text {ns }}$ & $827 \times 686^{*}$ & $884 \times 769^{\text {ns }}$ & $586 \times 786^{\mathrm{ns}}$ & $1833 \times 1266^{\mathrm{ns}}$ & 40,49 \\
\hline Número de ramos - $45 \mathrm{DAE}^{2} /$ & $1,45 \times 2,95^{*}$ & $1,5 \times 1,4^{*}$ & $1,7 \times 1,3^{\text {ns }}$ & $1,8 \times 0,9^{*}$ & $3,7 \times 2,2 *$ & 22,97 \\
\hline Número de ramos - $60 \mathrm{DAE}$ & $2,4 \times 4,0^{*}$ & $2,6 \times 2,2 *$ & $2,4 \times 2,9^{\text {ns }}$ & $2,3 \times 2,1^{\mathrm{ns}}$ & $4,2 \times 3,9^{\text {ns }}$ & 18,77 \\
\hline Comprimento do ramo $(\mathrm{cm})-45 \mathrm{DAE}$ & $7,3 \times 7,8^{\text {ns }}$ & $7,5 \times 7,1^{\mathrm{ns}}$ & $5,9 \times 9,0^{\text {ns }}$ & $8,9 \times 5,4^{\mathrm{ns}}$ & $8,7 \times 6,9^{\text {ns }}$ & 30,22 \\
\hline Comprimento do ramo $(\mathrm{cm})-60 \mathrm{DAE}$ & $10,4 \times 12,3^{\text {ns }}$ & $11,5 \times 9,4^{\text {ns }}$ & $10,3 \times 12,8^{\text {ns }}$ & $9,5 \times 9,3^{\text {ns }}$ & $13,0 \times 11,6^{\mathrm{ns}}$ & 21,43 \\
\hline
\end{tabular}

1/ Cultivares 1 a 6, respectivamente: IAS 5, BR-16, CD 205, Fepagro RS-10, BRS 205 e Cobb. ㄴ/ Dias após a emergência.

* ou ${ }^{\text {ns }}$ Contrastes significativos e não-significativos, respectivamente, a $5 \%$ de probabilidade. 


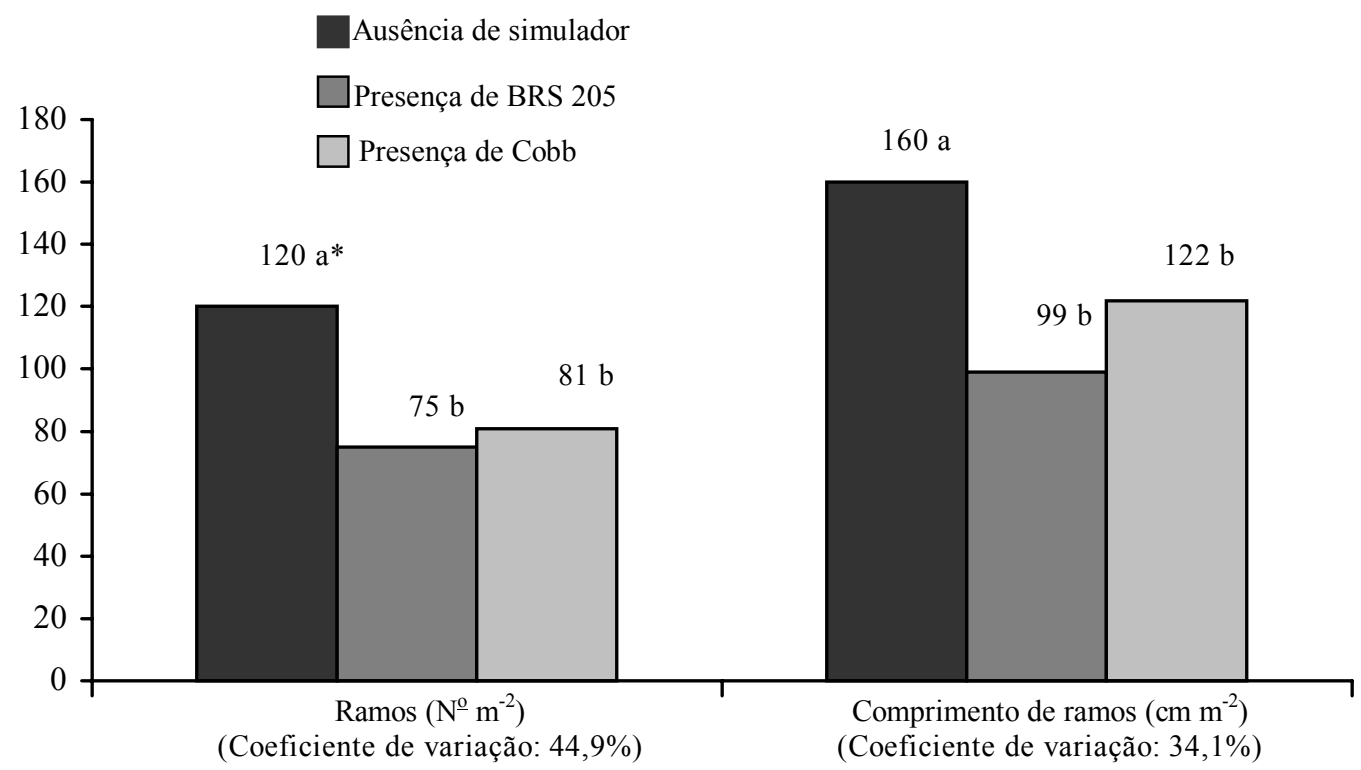

* Médias seguidas de mesma letra, em cada característica, não diferem pelo teste de Duncan a 5\% de probabilidade.

Figura 3 - Valores médios para número e comprimento de ramos por área no estádio fenológico $\mathrm{R}_{8}$, dos cultivares de soja reagentes (IAS 5, BR-16, CD 205 e Fepagro RS-10) à competição ou não dos cultivares BRS 205 e Cobb, simuladores de plantas daninhas. EEA/UFRGS, Eldorado do Sul-RS, 2002/03.

características número e comprimento de ramos, tenham contribuído para que eventuais diferenças entre os simuladores presentes não fossem significativas, tampouco as interações para os fatores estudados. Entretanto, considerando-se os valores absolutos obtidos, a presença de BRS 205 provocou reduções de 7,4 e de $18,8 \%$, respectivamente, nas duas variáveis dos cultivares reagentes, em comparação à presença de Cobb.

Nem sempre caracteristicas dissimilares entre plantas de cultivares de soja, especialmente quanto à estatura de planta, podem explicar completamente os efeitos morfofisiológicos verificados nas plantas em condição de competição, que seriam decorrentes, basicamente, da disputa por luz. É provável que a competição radical por água e nutrientes também tenha contribuído para afetar os resultados obtidos. Dessa forma, cultivares que apresentam características iniciais vantajosas na competição por luz com plantas concorrentes conseguirão manter a vantagem durante todo o ciclo se mostrarem, além do investimento na parte aérea, desenvolvimento de raízes que ocupem o espaço na busca concomitante por recursos do solo.
Os resultados evidenciam que cultivares de soja apresentam variação na velocidade de emergência de plântulas, e os cultivares Cobb, CD 205 e Fepagro RS-10 mostram elevados indices de velocidade de emergência. A velocidade de emergência de plântulas em cultivares de soja, por si só, não é indicadora adequada do crescimento inicial que se verifica posteriormente, embora Fepagro RS-10 tenha se destacado em ambas as características. Em geral, os cultivares Fepagro RS-10 e BR-16 desenvolvem elevados incrementos em parâmetros como estatura, área foliar e massa aérea de plantas em estádios iniciais de desenvolvimento, características próprias de plantas competitivas por luz. Cultivares de soja de ciclo precoce cobrem com mais rapidez o solo durante os primeiros 45 dias de ciclo, mas são superados posteriormente pelos cultivares de ciclo tardio.

\section{AGRADECIMENTO}

À Fundação de Amparo à Pesquisa do Estado do Rio Grande do Sul (FAPERGS), pelo apoio financeiro na execução deste trabalho. 


\section{LITERATURA CITADA}

BALBINOT, A. A. et al. Características de plantas de arroz e a habilidade competitiva com plantas daninhas. Planta Daninha, v. 21, n. 2, p. 165-174, 2003.

BALLARE, C. L.; CASAL, J. J. Light signals perceived by crop and weed plants. Field Crops Res., v. 67, n. 2, p. $149-160,2000$

BENNETT, A. C.; SHAW, D. R. Effect of Glycine max cultivars and weed control on weed seed characteristics. Weed Sci., v. 48, n. 4, p. 431-435, 2000.

BEWLEY, J. D. Seed germination and dormancy. Plant Cell, v. 9, n. 7, p. 1055-1066, 1997.

EMPRESA BRASILEIRA DE PESQUISA AGROPECUÁRIA - EMBRAPA. Sistema brasileiro de classificação de solos. Brasília: 1999. 412 p.

FIRBANK, L. G.; WATKINSON, A. R. On the analysis of competition within two-species mixtures of plants. J. Appl. Ecol., v. 22, n. 2, p. 503-517, 1985.

FISCHER, R. A.; MILES, R. E. The role of spatial pattern in the competition between crop plants and weeds. A theoretical analysis. Math. Biosci., v. 18, p. 335-350, 1973.

HORAK, M. J.; LOUGHIN, T. M. Growth analysis of four Amaranthus species. Weed Sci., v. 48, n. 3, p. $347-355,2000$.

INSTITUTE STATISTICAL ANALYSIS SYSTEM - SAS. User's guide: version 6.4 ed. Cary: 1989. $846 \mathrm{p}$.

KWON, S. L.; SMITH JR., R. J.; TALBERT, R. E. Interference durations of red rice (Oryza sativa) in rice (Oryza sativa). Weed Sci., v. 39, n. 3, p. 363-368, 1991.
MELGES, E.; LOPES, N. F.; OLIVA, M. A. Crescimento e conversão da energia solar em soja cultivada sob quatro níveis de radiação solar. Pesq. Agropec. Bras., v. 24, n. 9, p. 1065-1072, 1989.

POPINIGIS, F. Fisiologia da semente. Brasília: AGIPLAN, 1977. 289 p.

RADOSEVICH, S.; HOLT, J.; GHERSA, C. Weed ecology: implications for vegetation management. 2.ed. New York: Wiley, 1997. 589 p.

RAJCAN, I.; SWANTON, C. L. Understanding maize-weed competition: resource competition, light quality and the whole plant. Field Crops Res., v. 71, n. 2, p. 139-150, 2001.

REUNIÃO DE PESQUISA DE SOJA DA REGIÃO SUL, 31., 2003, Porto Alegre. Indicações técnicas para a cultura da soja no Rio Grande do Sul e em Santa Catarina 2003/ 2004. Porto Alegre: Universidade Federal do Rio Grande do Sul, 2003. $137 \mathrm{p}$.

RIBOLDI, J. Delineamentos experimentais de campo. Porto Alegre: Universidade Federal do Rio Grande do Sul, 1993. 71 p. (Cadernos de matemática e estatística).

SILVA, G. A. Métodos de unidades térmicas para estimativa do comportamento fenológico de genótipos de soja (Glycine Max (L.) Merrill). 1984. 131 f. Dissertação (Mestrado em Fitotecnia) -Universidade Federal do Rio Grande do Sul, Porto Alegre, 1984.

SIMS, B. D.; OLIVER, L. R. Mutual influences of seedling johnsongrass (Sorghum halepense), sicklepod (Cassia obtusifolia), and soybean (Glycine max). Weed Sci., v. 38, n. 2, p. 139-147, 1990.

WAX, L. M.; PENDLETON, J. W. Effect of row spacing on weed control in soybeans. Weed Sci., v. 16, n. 4, p. $462-465,1968$. 